Social Movement Studies,

Vol. 4, No. 1, 65-74, May 2005

Routledge

\title{
Building an Electronic Repertoire of Contention
}

\begin{abstract}
BRETT ROLFE
Sydney, Australia

ABSTRACT This short paper examines the way in which the electronic repertoire of contention for online social movements is being built, and the means by which it will continue to evolve. Drawing on the work of Tilly and Tarrow, a number of possible explanations are examined for innovation within the online activist space, and for the diffusion of that innovation. Analysis suggests that several of the current approaches to understanding repertoire innovation are useful in describing the developing online repertoire. A hybrid model is proposed, integrating several of these approaches to provide a holistic description of electronic repertoire innovation and diffusion.
\end{abstract}

KEY WordS: Repertoire of contention, online activism, cyber-activism, Internet, cyber-diffusion

Perhaps someday, as more people go online, then maybe these actions will create a tradition, create codes so people won't have to reinvent what to do. (Dominguez, 2002, p. 394)

The emergence of the Internet has had a significant effect on many aspects of society. One specific area of growth in recent years has been the use of digital technology by social movements. While the ubiquity of Internet access varies greatly within and between nations (Norris, 2001), it can still play an important role for a broad range of movement organizations. Mario Diani (2001) identifies the Internet as a tool for communication (private, public and mediated), organization, and motivation. It can be a channel for information collection and publication, a site for dialogue and debate, or a venue for lobbying and fundraising (Denning, 2001; Norris, 2002).

In addition to these roles, a number of organizations are employing the Internet as a platform for staging online direct action (ODA hereafter). ODA is the result of "extending the philosophy of activism and direct action into the "virtual" world of electronic information exchange and communication' (Electrohippies, 1999). Known variously as virtual activism, net protest, hacktivism, and cyberjamming, ODA is a rapidly growing and evolving field (Lasn, 2000, p. 132; Denning, 2001; Jordan, 2002). The importance of digital space as a site for contestation is increasing as the groups with which movements are contesting become

Correspondence Address: Brett Rolfe, PO Box 343, Glebe, NSW 2037, Australia. Tel.: +61 29571 5913; Email: brett@digitalstrategist.com

1474-2837 Print/1474-2829 Online/05/0100065-10 ㄷ 2005 Taylor \& Francis Group Ltd DOI: $10.1080 / 14742830500051945$ 
more vested in the online realm. The locus of power is becoming virtual, and to remain relevant the site of protest must accommodate this (Critical Art Ensemble, 1996).

Groups practising ODA deploy a range of tactics including cyberpetitions, virtual protests, virtual sit-ins, virtual blockades, gripe sites, email bombs, web hacks, and computer viruses (Lasn, 2000, pp. 132-133; Denning, 2001, p. 241). In a broad review of ODA, Graham Meikle suggests that 'the whole repertoire of tactics developed throughout the twentieth century, from the Suffragettes to Civil Rights, from Greenpeace to ACT UP, from Gandhi to Greenham Common, have found their digital analogues, as social activism moves into cyberspace' (2002, pp. 24-25).

However, not all ODA tactics are purely derivative of those used by existing social movements. Others have included the development of an 'electronic monument' and use of specially constructed software to block access to websites, 'creating a disturbance' (Dominguez, 2002, p. 387).

At this time, little research has been done to explain how this array of tactics has been developed and continues to evolve. This short paper examines several possible factors, and tentatively proposes a model for the innovation and diffusion of ODA.

An important concept in addressing these issues is the 'repertoire of contention', a term coined by Charles Tilly to describe 'the whole set of means [a group] has for making claims of different kinds on different individuals or groups' (1986, p. 4). Not only does this repertoire provide an array of possible tactics, it also limits activists, as 'people generally turn to familiar routines and innovate within them, even when in principle some unfamiliar form of action would serve their interests much better' (1986, p. 4). While more useful as a metaphor to structure analysis than a scientific instrument (Traugott, 1995, p. 3), the concept of a repertoire provides a framework for examining the development of tactics within social movements.

The notion of repertoire has been further developed by McAdam et al. (2001) as a locus around which varied performances are created. While this more improvisational approach suggests an inherently dynamic conception or repertoire, actions are still limited to modifications of accepted and understood routines (2001, p. 49).

Repertoire exists initially at the level of a specific group, where it describes the available means of contention for that group. However, as 'similar groups generally have similar repertoires, we can speak more loosely of a general repertoire that is available for contention to the population of a time and place' (Tilly, 1986, p. 4) (Figure 1).

Tarrow has also expanded on the concept in a way that is particularly relevant to ODA. He describes the 'modular' nature of certain elements of repertoire, manifest in the 'capacity of a form of collective action to be used by a variety of social actors, against a variety of targets, either alone, or in combination with other forms' (1998, p. 33).

The notion of repertoire can be extended into the area of ODA, giving rise to a 'repertoire of electronic contention' (Costanza-Chock, 2003, p. 1). This term will be used here to describe both the specific repertoire of an individual activist group practising ODA, as well as the total collection of online tactics deployed within the digital space by various groups.

In examining the development of this repertoire of electronic contention, it is necessary to look at how forms of online direct action are created, communicated, and sustained.

\section{Innovation within Social Movements}

In examining social movements generally, Tarrow initially suggested that innovation was the role of leaders, who 'invent, adapt and combine various forms of collective action 


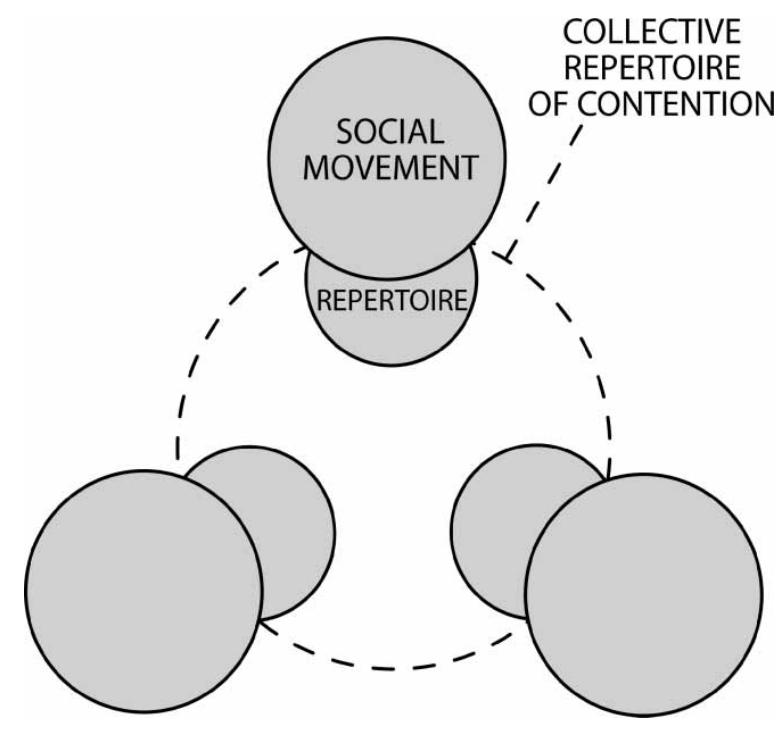

Figure 1. Specific and collective repertoires

to stimulate support from people who might otherwise stay at home' (1998, p. 19). While this adequately accounts for many historical events, Tarrow acknowledges that more recent movements often lack cohesive organizational structures and identifiable leaders $(1998$, p. 21).

Two alternative hypotheses put forward have been 'innovation at the margins' (Tarrow, 1998, p. 114) and 'moments of madness' (Zolberg, cited in Tarrow, 1995). Diametrically opposed in many ways, these approaches propose that innovation comes either from limited creativity around the current repertoire, or from large leaps during times of crisis. Regardless of the source of innovation, it is suggested that following innovation the repertoire evolves by absorbing those innovations that are most successful, and rejecting others that are not (Tarrow, 1995, p. 116).

Innovation at the margins is the most accepted account of change, proposing that contenders 'generally innovate at the perimeter of the existing repertoire rather than breaking entirely with old ways' (Tilly, 1995, p. 28).

In reviewing repertoire change within a range of movements, McAdam et al. comment that in almost all cases, innovative forms of action were not completely new, instead suggesting that changes were 'creative modifications or extensions of familiar routines' (2001, p. 49).

In examining ODA, Meikle found similarly that 'many online campaigns are continuations of existing struggles for justice and so inevitably continue to use the approaches honed offline' (2002, p. 24). In this way, the electronic repertoire of contention is being constructed through translation of elements of a more general repertoire into the online space (Figure 2).

Following Tilly, Meikle notes that adherence to existing repertoire appears to occur even when the tactics are problematic. The potentially flawed tactic of email petitions, for instance, continues to be widely used not because of its utility, but because of its familiarity (2002, p. 25). 


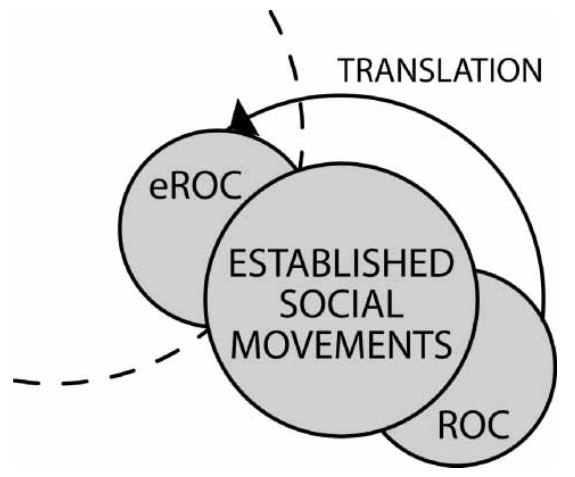

Figure 2. Translation as innovation at the margins

This notion echoes the media theory of Marshall McLuhan, who suggested that '[w]hen faced with a totally new situation, we tend always to attach ourselves to the objects, to the flavor of the most recent past. We look at the present through a rear-view mirror. We march backwards into the future' (McLuhan and Fiore, 1967, pp. 73-74). Meikle adopts this stance, seeing the generation of a derivative repertoire as 'an inevitable consequence of the way in which we adopt technological change' (2002, p. 24).

While there is merit in this approach when explaining the actions of established social movements with well-defined repertoires, it becomes problematic given the inherently novel nature of the Internet itself. Manuel Castells critiques this 'backing into the future', suggesting that ' $[u] n l i k e$ the mass media of the McLuhan Galaxy, [digital media] have technologically and culturally embedded properties of interactivity and individualization' (1996, p. 358).

While many instances of ODA can clearly be seen as improvisations within the limits that McAdam et al. suggest, other cases appear so specific to the Internet that an alternative explanation is required. Acknowledging this, it is perhaps necessary to look at 'moments of madness' to more thoroughly understand the development of the electronic repertoire of contention.

Several of the scholars who have discussed 'innovation at the margins' have also suggested that repertoires evolve in moments of crisis, where innovation results from struggle (Tilly, 1995, p. 26; McAdam et al., 2001, p. 49). Tarrow sees this process as a part of a cyclic model, where 'new forms of collective action develop within the experimental context of cycles of protest' (1995, p. 94). The most successful, transferable tactics are then adopted as part of a movement's repertoire for use during what Tarrow refers to as the 'quieter times' (1995, p. 94).

This approach is particularly strained in the digital space where 'the speed at which information can be disseminated affects the global diffusion of protest dramatically' (Ayers, 1999, p. 137). In an environment where tactics are shared between groups with a variety of agendas around the globe, can 'moments of madness' and 'quieter times' really be said to exist in any meaningful global sense?

In examining politically oriented movements, Tarrow has acknowledged that while many innovations in repertoire seem to first appear during crises, they are often developed in the ongoing daily practice of contention - it is merely that they are not sufficiently documented in coverage of events until points of crisis $(1998$, p. 45). This would suggest 
that the belief in innovation due to 'moments of madness' may say more about the visibility of tactics than the site of innovation. In order to locate the origin of tactics, it may be necessary to follow those tactics back to their source.

To isolate the source of an innovation, it is necessary to realize that tactics are shared within and between movements through diffusion - 'the process by which an innovation (any new idea, activity or technology) spreads through the population' (Giugni, cited in Ayers, 1999, p. 134). Diffusion is pivotal for social movements as it provides a mechanism for the transfer of forms of contention between movements (McAdam et al., 2001, p. 68).

Obviously, this process is affected by the available media, as discussed by Tarrow, who observed an increased capacity for diffusion as a result of print media (1998, p. 46).

Expanding on this in the wake of digital technology, Jeffrey Ayers uses the term 'cyberdiffusion' to describe 'the rapid, computer-generated dissemination of information around the world, without concern for geographic location' (1999, p. 133). This ability to diffuse innovation by high-speed, digital, global means makes the Internet 'one of the most potent meme-replicating mediums ever invented' (Lasn, 2000, p. 132). With regard to social movements, the Internet facilitates the transfer of 'protest ideas and tactics quickly and efficiently across national borders' (Norris, 2002, p. 208) (Figure 3).

This rapid cyber-diffusion makes innovation a problematic subject of study for ODA as ideas can spread in ways that are complex, instantaneous and difficult to trace. One example that has been well documented is a piece of software known as FloodNet, allowing an analysis of its diffusion. FloodNet is a tool that facilitates 'virtual sit-ins', disrupting the behaviour of target websites. It was developed and later distributed by a group called the Electronic Disturbance Theatre (EDT) (Meikle, 2000, pp. 140-156). One of the members of EDT, Ricardo Dominguez, provides an account of the cyber-diffusion of FloodNet;

We uploaded the [FloodNet] Disturbance Developers Kit at one minute after midnight in celebration of the sixth year of the Zapatista uprising. And twenty

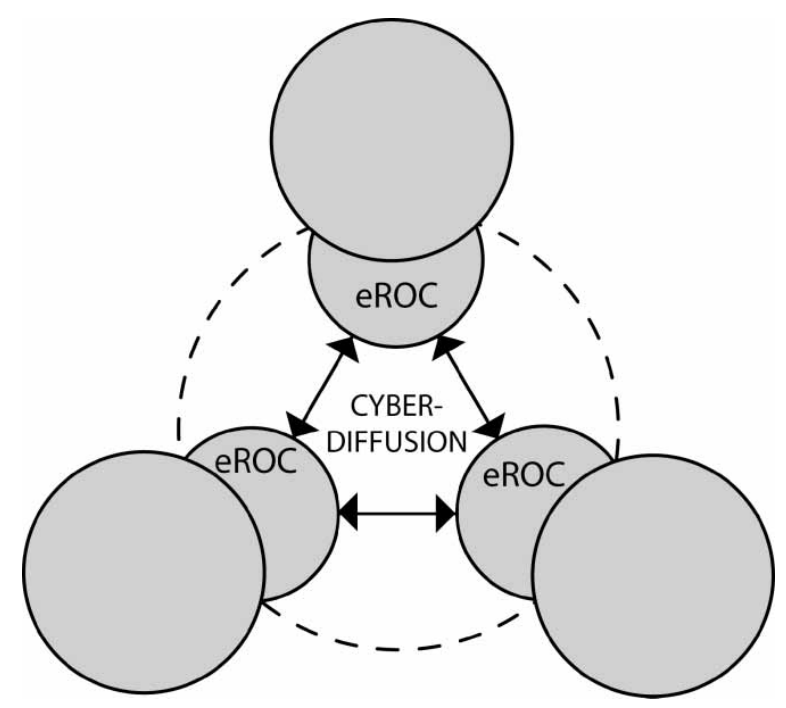

Figure 3. Cyber-diffusion of electronic repertoire 
minutes after we uploaded it here at Fakeshop.com, here in Williamsburg, Queer Nation did an action, a virtual sit-in, against GODHATESFAGS.com in Canada. A week later, the International Animal Liberation network did two actions against pharmaceuticals in Switzerland that went quite well. And then soon after that anti-arms activists in the UK did actions against arms dealer websites in the UK. (Dominguez, 2002, p. 391)

In exploring how the innovations that expand the electronic repertoire of contention are generated, it is necessary to examine the nature of groups such as EDT.

\section{Innovative Hothouses}

EDT is a group of four online activists who operated as a digital collective, staging activism in support of the Zapatista cause. Dominguez, who was instrumental in founding the group, had come from the Critical Art Ensemble (CAE), a similar small collective supporting a number of causes including AIDS awareness. The digital focus of CAE was inspired by the 'Panther Moderns', a fictitious group of cyber-terrorists in William Gibson's 'Neuromancer' (Gibson, 1986, p. 75) which CAE saw as the prototype of an 'activist electronic community' (Dominguez, 2002, p. 383).

Norris suggests that the movements most able to capitalize on the Internet are those that are flexible, well resourced, and technically adept (2002, p. 212). This is particularly evident where movements are striving to generate innovative means of online contestation. The key attributes of organizations such as EDT and CAE are a high level of critical awareness, technical expertise in various fields, small organizational structures, an innovative and cooperative mindset, and a flexible 'rolling agenda' (Meikle, 2002, p. 120) rather than alignment to a specific ideological cause. The structure for such an organization is described by CAE, which articulates a model for the constitution of a 'cell' effective for deploying ODA (Critical Art Ensemble, 1996, p. 23) (Figure 4).

These types of organizations act as 'hothouses' for innovation that can then be diffused to the broader activist community - who may be less skilled or more specifically engaged.

Dominguez also feels that the germinal state of the ODA space drives this activity. Analysing the use of the term 'hacktivism', he describes it as empty, suggesting that

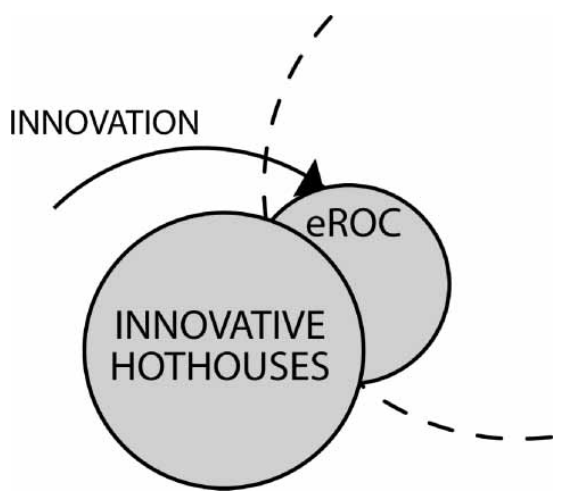

Figure 4. Innovative hothouses 
'empty terms do allow a certain kind of energetic invention, because people try to fill them' (Dominguez, cited in Meikle, 2002, p. 162).

As incubators for innovation, EDT and CAE are part of an expanding group of disparate organizations. While defining themselves as anything from 'design art collectives' to 'cultural corporations', similar activity and attitudes can be seen in the work of ${ }^{\mathrm{TM}}$ ark (pronounced 'artmark'), etoy.CORPORATION, the Electrohippies, the Cult of the Dead Cow and others. ${ }^{1}$

Driving radical innovation in the ODA space, some of these groups even ensure the modularity of tactics, and share them in ways that maximize diffusion. In distributing FloodNet, EDT intended that 'other cells, other groups would begin to emerge, not necessarily following the rules that we had set up' (Dominguez, 2002, p. 391).

While FloodNet is arguably the best-documented case of cyber-diffusion of an online tactic for contention, there are numerous other instances that corroborate this model of innovation. The practice of activist 'site-spoofing', for example, began with (c) ${ }^{\mathrm{TM}}$ ark developing the satirical GWBush.com site in 1999 (@) ${ }^{\mathrm{TM}}$ ark, 2000). The tactic generated considerable press coverage and ${ }^{\mathrm{TM}}{ }^{\mathrm{TM}}$ ark continued to work with splinter group The Yes Men to develop spoof sites in support of causes ranging from World Trade Organization protests to the Greenpeace campaign against multinational Shell. Shortly thereafter, Greenpeace employed the technique directly when it spoofed the Coca Cola site during the 2000 Olympic Games (Greenpeace, n.d.). Since then, other organizations have rapidly begun to adopt the tactic, from environmental group the Sierra Club (Hall, 2003) to US political campaigns both Republican (Wolverton, 2002) and Democrat (Gross, 2004). ${ }^{2}$ In a move towards modularizing the tactic, The Yes Men and several related groups have collaborated to develop Reamweaver, a user-friendly software application specifically for site spoofing. ${ }^{3}$

In certain cases, diffusion has carried an innovation outside the realm of online protest, such as the Cult of the Dead Cow's 'BackOrifice' hacking software, now also used by a wide range of non-activist groups (Jordan, 2002, p. 131). Non-software tactics have also been developed, including etoy's infiltration of online trading chat-rooms to destabilize corporate share prices (Wishart and Bochsler, 2003). While these examples provide tentative support for the model proposed here, the genealogical analysis of online tactics is an area of research requiring urgent attention. Over time, it will be important to monitor and analyse where such tactics are reused, and by whom.

In addition to the rapid nature of cyber-diffusion, the degree of innovation in these tactics is overshadowed by the way in which they are framed. This framing is often a conscious attempt to draw on acceptance of the existing repertoire, even when the resulting metaphors are strained. In choosing to call FloodNet a tool for 'virtual sit-ins', Dominguez was drawing on the established repertoire of non-violent activism. 'If I said "virtual sit-in", it had a kind of pedagogical usefulness that the term I would prefer "electronic civil disobedience" - did not have' (Dominguez, cited in Meikle, 2002, p. 26).

Despite these problematic factors, 'innovative hothouses' appear to act as incubators for innovation that can then be diffused to more established movement groups. Similar osmosis of creativity and innovation has been identified in the past. Avant-garde artistic movements such as Surrealism and Dadaism have pioneered techniques that have then been adapted to become part of the repertoire of social movements (Scott and Street, 2001). These artistic movements played a similar role to that being proposed for culturally progressive online groups such as CAE.

The importance of Guy Debord and the Situationist movement has been stressed in facilitating the successful translation of artistic innovation to activism (Plant, 1992). 
It is just this type of bridging role that CAE sees the need for in adapting the tactics of today's technological pioneers to social movements (Critical Art Ensemble, 1996, pp. 19-20). While CAE acknowledge the unpopularity of the notion of an avant-garde in the wake of recent critical theory, their work is a call to action for exactly that - the emergence of a 'technocratic avant-garde' (1996, p. 28).

Examining the various ways in which online means of contestation emerge, the development of an online repertoire of contention appears to be the result of three discrete processes. The first is the translation into the digital space of elements of the offline repertoire by established social movement organizations. Second is radical creativity by small, less cause-driven groups with critical and technical expertise. Finally, these innovations are then shared between organizations rapidly and globally through the process of cyber-diffusion. Given the relatively immature state of online activism, it seems reasonable to suggest that as the field of ODA becomes more established, a fourth process will emerge more prominently in which organizations modify the existing electronic repertoire by 'innovating at the margins' (Figure 5).

As well as the implications for ODA, this model raises questions as to the impact of these processes for offline collective action. Are the speed and range of cyber-diffusion making it an effective tool for sharing offline tactics as well as online ones? ${ }^{4}$ Will a reversal occur that sees certain online tactics translated into the physical world? While these questions will no doubt be addressed over time, the first step is to acknowledge the novelty and power of the processes that are shaping the nature of activism in the digital realm.

We've learned from Gandhi certain gestures for the streets that are now ingrained in us. What do we do? We march, we sit. But we can also create other protocols that will be understood just as simply, a certain notion of electronic civil disobedience.

(Dominguez, 2002, p. 394)

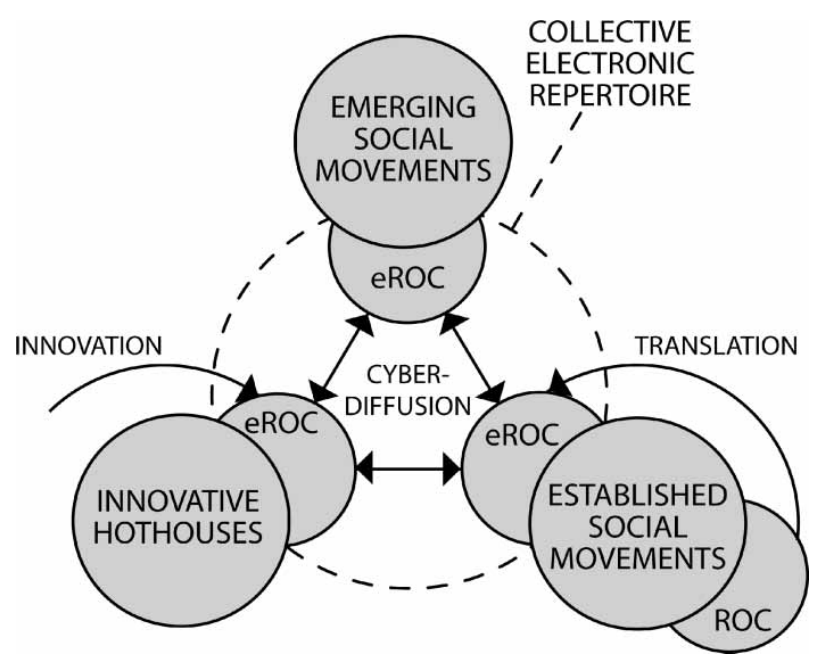

Figure 5. Proposed model for the development of an electronic repertoire of contention 


\title{
Acknowledgement
}

My gratitude to James Goodman for creating a rare environment of passionate debate.

\begin{abstract}
Notes
${ }^{1}$ This is by no means an exhaustive list of such organizations. The groups discussed in this article can be located online at http://www.cultdeadcow.com/ (Cult of the Dead Cow), http://www.etoy.com/ (etoy.CORPORATION), http://www.rtmark.com/ (ㄷ ${ }^{\mathrm{TM}}$ ark), http://www.fraw.org.uk/ehippies/ (Electrohippies collective - inactive at time of writing), http://www.critical-art.net/ (Critical Art Ensemble), http://www.theyesmen.org/ (The Yes Men). Material related to Electronic Disturbance Theatre and other projects can be found on Ricardo Dominguez's site: http://www.thing.net/ rdom/

${ }^{2}$ The spoof sites referred to above can be located online at http://www.gwbush.com/, http://www.wtoo. org/, http://www.gatt.org/, http://www.rtmark.com/shell/, http://www.hummdinger.com/, http://www. egray.org/, and http://www.gatax.com/

${ }^{3}$ The Reamweaver software application is distributed through http://www.reamweaver.com/

${ }^{4}$ While there is limited academic research on the effectiveness of cyber-diffusion of activist tactics, anecdotal evidence suggests that this is indeed the case. Groups such as Adbusters (http://adbusters.org) and the McInformation Network (http://www.mcspotlight.org) rely heavily on the Internet as a means for collaboration and the exchange of ideas.
\end{abstract}

\section{References}

Ayers, J. M. (1999) From the streets to the Internet: the cyber-diffusion of contention, Annals of the American Academy of Political and Social Science, 566, pp. 132-143.

Castells, M. (1996) The Information Age: Economy, Society and Culture. Vol. I: The Rise of the Network Society (Malden, MA: Blackwell).

Costanza-Chock, S. (2003) Mapping the repertoire of electronic contention, Paper presented at the World Summit on the Information Society.

Critical Art Ensemble (1996) Electronic Civil Disobedience and Other Unpopular Ideas (New York: Autonomedia).

Denning, D. E. (2001) Activism, hacktivism and cyberterrorism: the Internet as a tool for influencing foreign policy, in: J. Arquilla \& D. Ronfeldt (Eds) Networks and Netwar: The Future of Terror, Crime and Militancy (Santa Monica, CA: RAND).

Diani, M. (2001) Social movement networks: virtual and real, in: F. Webster (Ed.) Culture and Politics in the Information Age: A New Politics? (London: Routledge).

Dominguez, R. (2002) Electronic disturbance: an interview, in: S. Duncombe (Ed.) Cultural Resistance Reader (London: Verso).

Electrohippies (1999) 'Virtual sit-in' to coincide with WTO conference, in: S. Duncombe (Ed.) Cultural Resistance Reader (London: Verso).

Gibson, W. (1986) Neuromancer (Glasgow: Collins).

Greenpeace (n.d.) Cyberactivism Revolutionises Greenpeace Campaigns, Available at http://archive.greenpeace. org/cyberstory/cyberactivism.htm (accessed 9 May 2004).

Gross, D. (2004) New democratic web site tweaks perdue on taxes, Ledger Enquirer, 20 April. Available at http:// www.ledger-enquirer.com/mld/ledgerenquirer/news/breaking_news/8476741.htm (accessed 9 May 2004).

Hall, S. (2003) GM's Hummer Gets Spoofed by Sierra Club, Available at http://www.marketingwonk.com/ archives/2003/07/29/gms_hummer_gets_spoofed_by_sierra_club/index.php (accessed 9 May 2004).

Jordan, T. (2002) Activism! Direct Action, Hacktivism and the Future of Society (London: Reaktion Books).

Lasn, K. (2000) Culture Jam: The Uncooling of America (New York: HarperCollins).

McAdam, D., Tarrow, S. \& Tilly, C. (2001) Dynamics of Contention (New York: Cambridge University Press). McLuhan, M. \& Fiore, Q. (1967) The Medium in the Massage (Corte Madera, CA: Gingko Press).

Meikle, G. (2002) Future Active: Media Activism and the Internet (New York: Routledge).

Norris, P. (2001) Digital Divide: Civic Engagement, Information Poverty and the Internet Worldwide (Cambridge: Cambridge University Press).

Norris, P. (2002) Democratic Phoenix: Reinventing Political Activism (Cambridge: Cambridge University Press). 
74 B. Rolfe

Plant, S. (1992) The Most Radical Gesture: The Situationist International in a Post-Modern Age (London: Routledge).

(C) ${ }^{\mathrm{TM}}$ ark (2000) The Presidential Exploratory Committee, Available at http://www.rtmark.com/bush.html (accessed 9 May 2004).

Scott, A. \& Street, J. (2001) From media politics to e-protest? The use of popular culture and new media in parties and social movements, in: F. Webster (Ed.) Culture and Politics in the Information Age: A New Politics? (London: Routledge).

Tarrow, S. (1995) Cycles of contentious action: between moments of madness and the repertoire of contention, in: M. Traugott (Ed.) Repertoires and Cycles of Collective Action (Durham, NC: Duke University Press).

Tarrow, S. (1998) Power in Movement: Social Movements and Contentious Politics (Cambridge: Cambridge University Press).

Tilly, C. (1986) The Contentious French (Cambridge, MA: Harvard University Press).

Tilly, C. (1995) Contentious repertoires in Great Britain, 1758-1834, in: M. Traugott (Ed.) Repertoires and Cycles of Collective Action (Durham, NC: Duke University Press).

Traugott, M. (1995) Recurrent patterns of collective action, in: M. Traugott (Ed.) Repertoires and Cycles of Collective Action (Durham, NC: Duke University Press).

Wishart, A. \& Bochsler, R. (2003) Leaving Reality Behind: etoy vs. eToys.com and Other Battles to Control Cyberspace (New York: Ecco).

Wolverton, T. (2002) Spoof site no joke for eBay, CNet NEWS.com, 6 September. Available at http://news.com. com/2100-1017-956968.html (accessed 9 May 2004).

Brett Rolfe is a freelance digital communications strategist and a postgraduate researching new media at the University of New South Wales. He has worked in the Internet field in Australia for the past nine years, writes regularly for trade publications, and has spoken at numerous conferences including the Australian Marketing Institute's inaugural 'National e-Marketing' conference. 